УДК 611.146.2:612.67

\title{
ТРЕХМЕРНО-АНАТОМИЧЕСКИЙ АНАЛИЗ СОСУДИСТОГО РУСЛА ПОЧКИ
}

Кафаров Эдгар Сабирович доктор медицинских наук, профессор

Федоров Сергей Владимирович доктор медицинских наук, профессор

Докаева Таиса Султановна

Везирханов Абуселим Загидович аспиранты

ФГБОУ ВО «Чеченский государственный университет»

Аннотация: Установлено, что имеется как количественная, так и качественная разница почечных артерий третьего и четвертого звеньев (междолевые сосуды 1-го и 2-го порядка) по отношению к вариантам и типам ветвления ветвей главной почечной артерии и уровневой организации ее дихотомий и трихотомий.

Ключевые слова: Почка, артерия, вена, архитектоника, 3D-анализ.

\section{THREE-DIMENSIONAL ANATOMICAL ANALYSIS OF THE VASCULAR KIDNEY ROOM}

\author{
Kafarov Edgar Sabirovich \\ Fedorov Sergey Vladimirovich \\ Dokaeva Taisa Sultanovna \\ Vezirkhanov Abuselim Zagidovich
}

\begin{abstract}
It is revealed that regarding to the options and types of branching of the renal artery and level of hierarchy of its single units (dichotomies and trichotomy), in the kidneys at the different types of branching set amount and would the quality difference in the number of vessels of the third and fourth levels (interlobar blood vessels of the 1st, 2nd order).
\end{abstract}

Key words: Kidney, artery, vein, architectonics, 3D analysis. 


\section{Актуальность исследования.}

Как известно, существует множество вариантов ветвления внутриорганных артерий почек. Изучение вопроса вариабельности внутриорганной иерархии почки, о зонах кровоснабжения и особенностях распределения артерий в паренхиме этого органа человека на протяжении долгого времени является предметом интереса многих исследователей. $[1,6,7$, $10,11]$.

Тем не менее вплоть до сегодняшнего дня авторы не могут прийти к единой точке зрения о структуре внутриорганного артериального почечного русла. $[1,4,5,6,7,10]$.

К сожалению, не смотря на тот факт, что знание особенностей распределения внутриорганных сосудов почки с учетом типа ветвления артерий очевидно значимо при выполнении различных оперативных вмешательств на почках, какие-то конкретные данные об этом как таковые - отсутствуют.[2, 3, 8, $9,12]$.

\section{Цель исследования.}

Провести трехмерно-анатомический анализ артериального русла почки человека.

\section{Материалы и методы исследования.}

Для нашего исследования было изготовлено 116 коррозионных препаратов артериальной системы почек человека, приобретенных в рамках реализации гранта РФФИ согласно договору № 20-315-90008. Все коррозионные препараты сосудов почки для оцифровки подвергались 3D сканированию с использованием трехмерной микрокомпьютерной томографической системы «RayScan 130» (Германия). Полученные объемные модели артериального почечного русла использовались для установления в трехмерной (3D) проекции внеорганных ветвей почечной артерии количества и топографии артериальных сосудов в почечных воротах. Типы ветвления почечной артерии в воротах почки в трехмерной (3D) проекции: а) экстраорганное; б) интраорганное.

Все данные исследования, как и исследуемый материал были подвержены обработке методами вариационной статистики на компьютере IBM PC Intel Pentium, при помощи пакета статистических программ «Excel» (Ver. 7), набор текста и иллюстраций произведен в программе «Word» (Ver. 7).

\section{Результаты исследования и их обсуждение.}


Нами проведен трехмерный анализ артериального сосудистого русла почки с выявлением звеньев и сосудов 3-го и 4-го порядка.

1. Так, считаем нужным особо отметить группу коррозионных препаратов, где главная почечная артерия - «A. renalis» (I)» делилась на две ветви, (на 44 препаратах), экстраренально, что наблюдалось 69,8 \% случаев. При этом, на 24 коррозионных препаратах вентральная ветвь главной почечной артерии делилась в среднем на $(\mathrm{X} \pm \mathrm{m}) 4 \pm 1$ сосуда 3-го порядка - «А. interlobares - 1» (III) и от 4 до 6 сосудов 4-го порядка - «A. Interlobares -2» (IV), а дорсальная делилась в среднем на $(\mathrm{X} \pm \mathrm{m}) 3 \pm 1$ и от 4 до 8 сосудов 4-го порядка - «A. Interlobares - 2» (IV), веерообразно расходившись от места своего формирования, распределяясь в вентральных и дорсальных отделах паренхимы почки, что мы встретили 30,0 \% случаев.

На 16 коррозионных препаратах вентральная ветвь главной почечной артерии - «A. renalis» (I)» делилась в среднем на $(\mathrm{X} \pm \mathrm{m}) 3 \pm 1$ сосуда 3-го порядка - «A. interlobares - 1» (III) и от 4 до 7 сосудов 4-го порядка - «А.

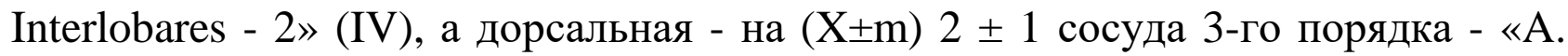
interlobares - 1» (III) и от 4 до 6 сосудов 4-го порядка - «A. Interlobares - 2» (IV), что мы встретили 25,3 \% случаев. На 4 коррозионных препаратах вентральная и дорсальная ветви почечной артерии делились в среднем на $(\mathrm{X} \pm \mathrm{m})$ на $3 \pm 1$ сосуда 3-го порядка и от 5 до 7 сосудов 4-го порядка - «A. Interlobares - 2» (IV), что мы встретили 6,3\% случаев.

2. Как было сказано выше из 63 коррозионных препаратов на 19 главная почечная артерия - «A. renalis» (I)» делилась интраренально, что составило 30,1 \% случаев. При данном варианте на 11 коррозионных препаратах артериальных сосудов почек из 19 передняя ветвь главной почечной артерии в разветвлялась на $(\mathrm{X} \pm \mathrm{m}) 3 \pm 1$ сосуда 3 -го порядка - «A. interlobares - 1» (III) и от 4 до 8 сосудов 4-го порядка - «A. Interlobares - 2» (IV), а дорсальная - на $2 \pm 1$ и от 6 до 8 сосудов 4-го порядка - «A. Interlobares - 2» (IV), которые распределялись в вентральных и дорсальных отделах почечной паренхимы, что мы встретили 17,4 \% случаев. На 5 коррозионных препаратах из 19 вентральная ветвь главной почечной артерии - «A. renalis» (I)» делилась в среднем на $(\mathrm{X} \pm \mathrm{m}) 4 \pm 1$ сосуда 3го порядка и от 6 до 8 сосудов 4-го порядка - «A. Interlobares - 2» (IV), a дорсальная - на $(\mathrm{X} \pm \mathrm{m}) 2 \pm 1$ и от 4 до 6 сосудов 4-го порядка - «A. Interlobares 2» (IV), что мы встретили 7,9 \% случаев. 
На 3 коррозионных препаратах из 19 вентральная и дорсальные ветви главной почечной артерии - «A. renalis» $(\mathrm{I}) »$ делились в среднем на $(\mathrm{X} \pm \mathrm{m}) 4 \pm 1$ сосуда 3-го порядка - «A. interlobares - 1» (III) и от 4 до 6 сосудов 4-го порядка «A. Interlobares - 2» (IV), что мы встретили 4,7 \% случаев.

3. Как было отмечено нами выше, главная почечная артерия в 15,5\% случаев (на 18 препаратах) - «A. renalis» (I)» относительно горизонтальной плоскости делилась на верхнюю полюсную и нижнеполюсную артерии. При этом на 9 коррозионных препаратах верхнеполюсная и нижнеполюсная ветви главной почечной артерии делились в среднем на $(\mathrm{X} \pm \mathrm{m}) 3 \pm 1$ сосуда 3-го порядка - «A. interlobares - 1» (III) и от 4 до 5 сосудов 4-го порядка - «А. Interlobares - 2» (IV), что мы встретили 7,7 \% случаев.

На 5 коррозионных препаратах верхнеполюсная ветвь главной почечной артерии - «A. renalis» (I)» делилась в среднем на $(\mathrm{X} \pm \mathrm{m}) 3 \pm 1$ сосуда 3-го порядка и от 5 до 6 сосудов 4-го порядка - «A. Interlobares - 2» (IV), которые распределялись в передних и задних отделах верхнего полюса почки, а нижнеполюсная на $(\mathrm{X} \pm \mathrm{m}) 2 \pm 1$ сосуда 3-го порядка - «A. interlobares - 1» (III) и от 5 до 7 сосудов 4-го порядка - «A. Interlobares - 2» (IV), которые распределялись также в вентральных и дорсальных отделах нижнего полюса почки, что мы встретили 4,3 \% случаев.

На 4 коррозионных препаратах верхнеполюсная ветвь главной почечной артерии - «A. renalis» (I)» отдавала в среднем $(\mathrm{X} \pm \mathrm{m}) 2 \pm 1$ сосуда 3 -го порядка и от 3 до 5 сосудов 4-го порядка - «A. Interlobares - 2» (IV), а нижнеполюсная артерия в среднем по $(\mathrm{X} \pm \mathrm{m}) 3 \pm 1$ и от 4 до 6 сосудов 4-го порядка, что мы встретили 3,4 \% случаев. Далее, как было выявлено на 35 коррозионных препаратах артериальных сосудов почек из 116 «A. renalis» (I)» в $30 \%$ случаев разделялась на три отдельных ветви. При этом, из упомянутых 35 коррозионных препаратов в 12,9 \% случаев (на 15 коррозионных препаратах) главная почечная артерия - «A. renalis» (I)» делилась на переднюю, заднюю и ветвь верхнего полюса почки относительно как фронтальной, так и горизонтальной плоскостей.

На 8 коррозионных препаратах из 15 вентральная ветвь главной почечной артерии в среднем делилась на $(\mathrm{X} \pm \mathrm{m}) 3 \pm 1$ сосуда 3 -го порядка - и от 4 до 6 сосудов 4-го порядка - «A. Interlobares - 2» (IV), которые распределялись в вентральных отделах нижнего полюса почки, а дорсальная - на $(\mathrm{X} \pm \mathrm{m}) 2 \pm 1$ и от 4 до 8 сосудов 4-го порядка, которые распределялись в дорсальных отделах, а 
верхнеполюсная делилась в среднем на $(\mathrm{X} \pm \mathrm{m}) 3 \pm 1$ сосуда 3 -го порядка - «А. interlobares - 1» (III) и от 4 до 6 сосудов 4-го порядка, которые распределялись в вентральных и дорсальных отделах верхнего полюса почки, что мы встретили $6,8 \%$ случаев. На 4 коррозионных препаратах из 15 вентральная ветвь главной почечная артерия делилась в среднем на $(\mathrm{X} \pm \mathrm{m}) 3 \pm 1$ сосуда 3-го порядка - «A. interlobares - 1» (III) и от 3 до 5 сосудов 4-го порядка - «A. Interlobares - 2» (IV), дорсальная - на $3 \pm 1$ и от 4 до 6 сосудов 4-го порядка, а верхнеполюсная делилась в среднем на $(\mathrm{X} \pm \mathrm{m}) 3 \pm 1$ сосуда 3 -го порядка и от 3 до 7 сосудов 4-го порядка - «A. Interlobares - 2» (IV), что мы встретили 3,4 \% случаев.

На 3 коррозионных препаратах из 15 вентральная ветвь главной почечной артерии делилась в среднем на $(\mathrm{X} \pm \mathrm{m}) 4 \pm 1$ сосуда 3-го порядка и от 4 до 6 сосудов 4-го порядка - «A. Interlobares - 2» (IV), дорсальная ветвь - на $3 \pm 1$ и от 4 до 6 сосудов 4-го порядка, а верхнеполюсная в среднем делилась на $(\mathrm{X} \pm \mathrm{m}) 2 \pm$ 1 сосуда 3-го порядка - «A. interlobares - 1» (III) и от 3 до 5 сосудов 4-го порядка - «A. Interlobares - 2» (IV), что мы встретили 2,5 \% случаев.

\section{Выводы.}

Таким образом, если брать во внимание типы ветвления отдельно взятых ветвей почечной артерии внутри самого органа и уровневой организации ее отдельно взятых звеньев (дихотомий и трихотомий), несложно заметить как определенную количественную, так и качественную разницу в числе сосудов третьего и четвертого звена (междолевые сосуды 1-го, 2-го порядка), если считать эти сосуды «сегментарными». Так, число этих сосудов может составлять 10 или даже более в подавляющем числе случаев, если брать во внимание 3-й уровень дихотомий, то есть деление передних, задних в ветвей верхнего и нижнего полюса почки. Из чего можно заключить, что «сегментарными» артериями можно называть в одной и тоже почке, в которой встречаются различные типы ветвления внутриорганных артерий, как сосуды четвертого, так и третьего звеньев, все зависит от уровня дихотомий.

\section{Список литературы}

1. Азми, Махмуд Венозное русло и его синтопические взаимоотношения с артериями почек человека [Текст] / Азми Махмуд, Али Хуссейн // Медицина сьогодні і завтра. - 2008. - № 2. - С. 101-104. 
2. Асфандияров, Ф.Р. Тезисы докладов V конгресса Международной Ассоциации Морфологов [Текст] / Ф.Р. Асфандияров // Морфология. - 2000. T.117. - № 3.

3. Бурых М.П. Анатомия чашечно-лоханочного комплекса почки человека в постнатальном онтогенезе. - Харьков; - 2000; - 84 с. 27.

4. Валишин, Э.С. Казанский медицинский государственный университет [Текст] / Э.С. Валишин // Тезисы докладов VI конгресса Международной Ассоциации Морфологов. - 2002. - Т.121, № 2.

5. Дгебуадзе, М.А. [Текст] / М.А. Дгебуадзе, Р.Г. Хецуриани // Тезисы докладов VI конгресса Международной Ассоциации Морфологов. - Тбилиси, 2002. - Т. 21., № 2-3.

6. Каплунова, О.А. Сравнительные данные об особенностях внутриорганных венозных сосудов почек в норме и при ишемической болезни сердца [Текст] / О.А. Каплунова // Морфология. - 2008. - Т. 133, № 2. - С. 58.

7. Кафаров Э.С. Вариантная анатомия почечной артерии и её ветвей. Автореферат диссертации кандидата медицинских. Волгоград; - 2004; 19 с.

8. Квятковская Т.А., Чернявский Е.Х., Куцак Т.Л. Структурные особенности сосудов почек. // Российские морфологические ведомости. // № 12. - Москва. - 2000. -С.201.

9. Лопаткин, Н. А. Современные подходы к лечению рака почки // Перспективные направления диагностики и лечения рака почки [Текст] / Н.А. Лопаткин, С.П. Даренков / Рос. об-во урологов; Всерос. ассоц. радиологов. М., 2003. - C. 156-157.

10. Мочалов, О. Индивидуальная изменчивость архитектоники кровеносных сосудов почки [Текст]: Автореф. дис. докт. мед. наук / О. Мочалов / Министерство Здравоохранения и Социальной защиты Республики Молдова. Государственный Университет Медицины и Фармации им. Н.А. Тестемицану. 2006. - 17 c.

11. Соколов, В.В. Возрастные особенности архитектоники сосудов почек [Текст] / В.В. Соколов, О.А. Каплунова, А.В. Соковцева // Архив анатомии, гистологии и эмбриологии. - 1991. - Т.100, № 2.

12. Соколов В.В., Каплунова О.А. Артериальные сосуды почек в норме и при некоторых сердечно-сосудистых заболеваниях. // Ростов-на-Дону., изд. РостМУ. - 2001. -147 c. 